\title{
Lenguaje cinematográfico como proyecto de aprendizaje para estudiantes de la especialidad de inglés en el Grado de Educación Primaria
}

\author{
JOSÉ VÍCTOR VILLALBA GÓMEZ \\ Universidad de Murcia - España \\ Recibido el 28-06-16; primera evaluación el 11-07-18; \\ segunda evaluación el 14-08-19; tercera evaluación el \\ 15-08-19; aceptado el 21-08-19
}

\section{Resumen}

Inspirado en proyectos educativos basados en hacer cine en la escuela, el presente artículo muestra un proyecto audiovisual para estudiantes de la especialidad de inglés del Grado de Educación Primaria de la Universidad de Murcia. Para conocer la respuesta de nuestros alumnos ante este tipo de propuestas, indagamos en un pretest cumplimentado antes y un test después del desarrollo de la misma, extrayendo relevante información acerca de los conocimientos, habilidades y actitudes de nuestros estudiantes ante el proceso creativo, el manejo de herramientas audiovisuales, las TIC y sus posibilidades didácticas. Finalmente, se ha realizado un análisis iconográfico de los dieciséis cortometrajes realizados. El objetivo principal es comprobar la respuesta de los alumnos, futuros maestros, ante la práctica de metodologías de Aprendizaje Basada en Proyectos Artísticos (ABPA).

Palabras clave: educación artística, proyecto audiovisual, Grado de Educación Primaria.

\footnotetext{
* Doctor en el Área de Didáctica de la Expresión Plástica de la Universidad de Murcia. Desarrolla su actividad docente e investigadora en la Facultad de Educación. Como investigador ha publicado en revistas como Educatio Siglo XXI y Arte, Individuo y Sociedad, además de participar en más de quince congresos internacionales y en proyectos de investigación e innovación en la Universidad de Murcia. Correo electrónico: josevictor.villalba@um.es
} 


\section{Linguagem cinematográfica como projeto de aprendizagem para estudantes da especialidade de inglês no Ensino Básico}

\section{Resumo}

Inspirado em projetos educacionais de cinema na escola, este artigo apresenta um projeto audiovisual para alunos da especialidade de inglês do Grau de Ensino Básico da Universidade de Murcia. Para conhecer a resposta dos nossos alunos diante deste tipo de proposta, estudamos um pré-teste realizado antes e depois do desenvolvimento do mesmo, extraindo informaçôes relevantes sobre os conhecimentos, habilidades e atitudes dos nossos alunos antes do processo criativo, da gestấo de ferramentas audiovisuais, das TIC e suas possibilidades didáticas. Finalmente, foi realizada uma análise iconográfica dos dezesseis curtas feitos. O objetivo principal é a resposta dos alunos do Grau, futuros professores, antes da prática de Metodologias de Aprendizagem Baseadas em Projetos Artísticos (ABPA).

Palavras-chave: educação artística, projeto audiovisual, Licenciatura em Ensino Básico

\section{Cinematographic language as project for the students from Primary Education Degree (English speciality)}

\section{Abstract}

Inspired by educative projects based on «making films at school», this article shows an audiovisual project for Primary Education Degree (English speciality) students from the University of Murcia. To know the answer of our students when faced with this kind of proposal, we looked into it through two tests, one before and another after of said activity, obtaining relevant information about the knowledge, abilities and attitude of our students regarding the creative process, the use of audiovisual tools, the TIC and their educational possibilities. Lastly, an iconographic analysis of the sixteen short films made was also performed. The main goal is to check the response of students (future school teachers) when faced with Project-Based Artistic Learning (PBAL) methodologies.

Keywords: artistic education, audiovisual project, Primary Education Degree. 


\section{INTRODUCCIÓN}

Inspirado en proyectos educativos de las décadas de 1980 y 1990, basados en hacer cine en la escuela, el presente artículo muestra el proceso, los resultados y las conclusiones de un proyecto audiovisual para estudiantes de la especialidad de inglés del Grado de Educación Primaria de la Universidad de Murcia, todos nativos digitales de primera generación. Para conocer la respuesta de nuestros alumnos ante este tipo de propuesta didáctica, indagamos en un pretest cumplimentado antes y un test después del desarrollo de la misma, extrayendo relevante información acerca de los conocimientos, habilidades y actitudes de nuestros estudiantes ante el proceso creativo, el manejo de herramientas audiovisuales, las TIC y sus posibilidades didácticas. Finalmente, se ha realizado un análisis iconográfico de los dieciséis cortometrajes. El proyecto está basado en la creación de una narrativa con temática británica, basada en un viaje cultural, a través del desarrollo de los roles más importantes del lenguaje cinematográfico. El objetivo principal es comprobar la respuesta de los alumnos del Grado de Educación Primaria, futuros maestros, ante la práctica de metodologías de Aprendizaje Basada en Proyectos (ABP), aplicando contenidos propios de la Educación Artística, el lenguaje visual y las TIC, de forma que puedan ser utilizados transversalmente para otras asignaturas, en este caso, la asignatura de inglés, una de las áreas con mayor carga lectiva según el Real Decreto español 126/2014.

Como afirman Mudet, Beltran y Moreno (2015), «el arte puede ejercer como herramienta educativa en donde es posible desarrollar habilidades emocionales, mentales y comunicativas» (p. 319). A nivel formativo, para estudiantes del Grado, futuros maestros, resulta fundamental la transmisión de este concepto.

\section{Marco teórico}

La formación creativa del niño a través de la Educación Artística es necesaria para desarrollar sus capacidades cognitivas, emocionales, comunicativas, socioafectivas y motrices (Marín-Viadel, 2003). Para ello, es posible no solo a través de la asignatura especializada en Educación y Expresión Artística, sino como recurso instrumental. La Unesco (2006), en el libro de ruta para la Educación Artística, ya puso de manifiesto las razones por las que se hace imprescindible trabajar esta disciplina curricular. Además de crear el compromiso, se creó un horizonte educativo a partir de una serie de objetivos, enfoques, estrategias básicas y recomendaciones que se pactaron en la conferencia mundial 
sobre la Educación Artística: construir capacidades creativas para el siglo XXI. Son numerosas las formas de hacer cumplir el libro de ruta de la Unesco, y dentro de los compromisos pactados, materializar los objetivos: garantizar el cumplimiento del derecho humano a la educación y la participación en la cultura, desarrollar las capacidades individuales, mejorar la calidad de la educación y fomentar la expresión de la diversidad cultural.

Algunos de los caminos metodológicos para cumplir con los objetivos propuestos es a través del uso de la metodología de Aprendizaje Basado en Proyectos Artísticos (ABPA), desarrollando programaciones didácticas (Hervás, 2015) o programaciones que se fundamentan en la Investigación en Educación Artística (Roldán y Marín-Viadel, 2014).

Dentro de este tipo de proyectos es de obligada mención aquellos que incluyen las TIC y las ciencias audiovisuales, utilizando aquellos medios en los que el discente ha nacido y crecido, rodeados de tecnología: cámaras fotográficas, cámaras de video, teléfonos, internet, videojuegos, redes sociales, etc.; en definitiva, medios cotidianos para el niño, especialmente para aquellos nacidos a partir de la última década del siglo XX: los nativos digitales (Piscitelli, 2009).

Ante la situación actual de enormes cambios tecnológicos y curriculares, trabajar las TIC como recurso metodológico que fomente el trabajo colaborativo y dinamizador, independientemente del nivel educativo, tiene una importante proyección en procesos de innovación educativa (Hernández y Martín, 2017). Respecto a estas metodologías, ya anticipaba Calzadilla (2002) que:

Pueden producirse experiencias positivas de aprendizaje cuando los alumnos comparten sus descubrimientos, se brindan apoyo para resolver problemas $y$ trabajan en proyectos conjuntos. Por otra parte, la tecnología interactiva permite desarrollar, extender y profundizar las habilidades interpersonales, y penetra las barreras culturales a medida que estudiantes y docentes aprenden a comunicarse. (p.2)

Con trabajos como los de Ferro, Martínez y Otero (2009), GarcíaValcárcel, Hernández y Recamán (2012), y de García-Valcárcel, Basilotta y López (2014); se evidencia que, desde una múltiple óptica docente en etapas educativas, tanto no universitarias como universitarias, existen diversas ventajas de uso de las TIC en el proceso de enseñanza-aprendizaje. Respecto a aquellos recursos TIC relacionados con el campo audiovisual, existen una serie de trabajos vinculantes a este artículo que abordan temáticas como los lenguajes fílmicos o el cine en las aulas, líneas conceptuales y metodológicas paralelas a la que tratamos en este artículo. A finales de los noventa, propuestas 
como la de Bellido (1998) y Miravalles (1998), ya nos mostraban cómo a través de la lectura y comprensión del cine es posible desarrollar en el aula contenidos curriculares y transformar el vidente ciego en vidente crítico. También podemos corroborar con estas propuestas cómo es posible desarrollar contenidos curriculares a través de la propia práctica, asumiendo y ejercitando los roles cinematográficos con los primeros nativos digitales. Más recientemente, trabajos como los de Prendes, Castańeda y Gutierrez (2010), el de Clarembeaux (2010) y el de Marzábal y Aracena (2016); valoran la necesidad de adquirir recursos y competencias TIC para los docentes, entre ellos, los relacionados al sector cinematográfico.

A los precedentes citados, debemos sumar propuestas educativas audiovisuales que en su momento incitaron a la creación de este trabajo, y que dan testimonio de iniciativas y experiencias educativas como las que puso en marcha el maestro Don Pascual Vázquez Gómez, desde finales de la década de 1970 hasta su jubilación en el año 2006 en el Colegio Público Cristo del Consuelo de Cieza (Murcia). Sus trabajos educativos cinematográficos, derivados de su proyecto el cine en la escuela, iniciado en Super 8, llegaron a estar premiados en certámenes nacionales e internacionales. A través de una entrevista personal a Don Pascual Vázquez y la visualización de las entrevistas de TVE en los programas Revista de Cine (1980), Pista Libre (1982) y El Plummer (1986); se ha podido comprobar la transcendencia de su proyecto. A continuación, el maestro, a sus 77 años, rescata y detalla algunos de los premios conseguidos con películas grabadas con sus alumnos:

En 1981, en París, obtuvimos el máximo galardón en el Certamen Internacional X Musa por la película Futuribles, otorgado por el Centro Internacional de Cine para la Infancia y juventud, dependiente de la Unesco. En el mismo ańo, la misma película obtuvo el Segundo Premio en el Certamen Internacional de Cine para la Infancia y la Juventud de Gijón. En 1984, con la película Futuribles II obtuvimos el premio al Mejor Guion en la campaña «Hagamos Cine» del Centro Español de Cine para la Infancia y la Juventud. Se obtuvieron más premios de carácter internacional hasta 1996, por ejemplo, en el Concurso Internacional de Cine Joven organizado por Naciones Unidas en Viena. Lo más importante es que el alumnado aprendió a expresarse y a leer a través de la imagen, haciendo uso del proceso creativo y técnico que conlleva hacer y ver cine (P. Vázquez, comunicación personal, 2 de febrero de 2018). 
Figuras 1 y 2. Capturas de pantalla del programa de TV1
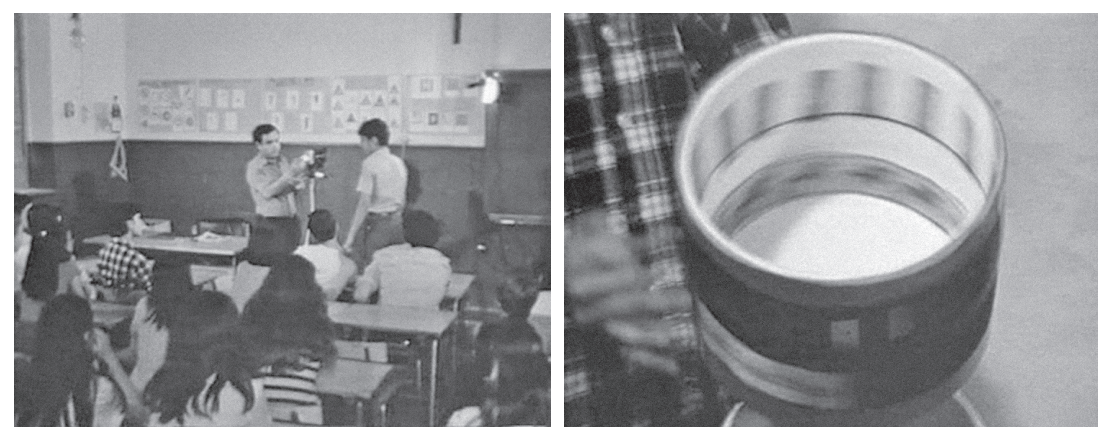

Fuente: Grabación de la Revista de cine, procedente de los archivos audiovisuales de Pascual Vázquez.

Sin embargo, a finales del siglo pasado, trabajos como los de Pérez y Aguaded (1994) ya hacían propuestas transversales similares a los proyectos audiovisuales de Pascual Vázquez, por lo que no podemos hablar de líneas metodológicas aisladas, sino de una línea de trabajo didáctico en diferentes centros educativos en los que se utilizaban la imagen fija, la imagen secuenciada, la imagen auditiva, la imagen gráfica, la imagen en movimiento y la imagen multimedia. Otras propuestas didácticas, a través del video en la escuela en aquella época, son las de Fandos (1994), Morilla (1994), Ruiz (1994) y Arenas (1995); en todas ellas se plantean cómo aprender y enseñar con los medios.

Actualmente, es tal la magnitud de medios tecnológicos que manejamos, especialmente, los relacionados con lo audiovisual, los cuales no podemos dejar de insistir como herramientas y métodos didácticos, ya no solo como consumidores y críticos de productos audiovisuales, siendo conscientes de la pedagogía tóxica y distinguiendo la realidad de la hiperrealidad (Acaso, 2009), sino como creadores, desarrollando proyectos educativos a partir de recursos TIC y audiovisuales, especialmente los cinematográficos.

Es cierto que, de los trabajos citados, en la mayoría de los casos, ha pasado mucho tiempo y la tecnología ha cambiado notablemente. Sin embargo, para este trabajo, consideramos que es importante hacer un pequeño ejercicio retrospectivo y recordar aquellas etapas que marcaron una época, la cual se refiere a la incorporación del cine como recurso educativo. Estos proyectos fueron la semilla para otros proyectos más actuales. En este sentido, uno de los escaparates actuales para visionar trabajos educativos basados en hacer cine es Edusiona't amb les arts (Valencia Extra, 2016). El evento tuvo lugar 
el 7 de julio de 2016 en Valencia, concretamente en el Centro del Carmen, en el museo del Siglo XVIII. En dichas jornadas, participaron entidades mediante demostraciones, conferencias, talleres, actuaciones y exposición de materiales; no pasando desapercibida la cantidad de proyectos artísticos que, extrapolando métodos de creación y expresión artística al terreno didáctico, trabajan por un aprendizaje significativo en el que integran la educación no formal con la reglada. Es en este contexto donde se sitúan distintos organismos, museos y entidades privadas, sobre todo empresas, asociaciones y fundaciones que presentan propuestas que tratan de compensar la situación cultural y artística a la que está sometido el currículum actual.

Las disciplinas en las que estas empresas desarrollan y fundamentan sus propuestas pertenecen a campos de escenografía, música, danza, artes plásticas, literatura y cinematografía, siendo esta última la más interesante para este trabajo. Las propuestas colocan la figura del maestro o especialista como mediador, que sirve de catalizador entre la propuesta y el alumno, canalizando multidisciplinarmente un ámbito cultural con metodologías interactivas que implican al alumnado de modo polisensorial. En este sentido, el método cobra especial protagonismo, enriqueciendo las posibilidades didácticas y creativas. Algunas de las instituciones y empresas que participaron pertenecen a profesionales audiovisuales, muy relacionados con el sector de la comunicación, especialmente la televisión.

\section{Metodología}

Este artículo pone a la práctica una metodología basada en proyectos, concretamente un proyecto artístico audiovisual para alumnos de la Mención de Inglés del Grado de Educación Primaria de la Universidad de Murcia. Se realiza un análisis cualitativo y cuantitativo de información multifuente (cuestionarios, observación participante, observación iconográfica, diarios individuales, grupos de discusión y entrevistas) en el que se detalla el conocimiento y habilidades previas del alumnado, las habilidades, conocimientos y opiniones una vez finalizado el proyecto, así como los resultados iconográficos de las producciones audiovisuales.

El cuestionario utilizado es una batería de preguntas divididas en dos partes, para antes de la puesta en práctica del proyecto y para una vez finalizada. La medición se ha efectuado mediante la escala Likert.

En la siguiente tabla, se muestran los objetivos del proyecto y los instrumentos de recogida, y análisis de información. 
Tabla 1. Objetivos y recogida y análisis de la información.

\begin{tabular}{ll}
\hline \multicolumn{1}{c}{ Objetivos } & \multicolumn{1}{c}{ Recogida y análisis de Información } \\
\hline Poner en práctica procesos creativos a través del & 1. Pretest \\
lenguaje audiovisual para la creación de recursos & 2. Informes escritos. \\
didácticos audiovisuales en Educación Primaria. & 3. Observación directa. \\
& 4. Análisis del trabajo audiovisual. \\
& 5. Postest \\
\hline
\end{tabular}

Analizar las habilidades, conocimientos

y opiniones del alumnado con respecto a

ABPA, especialmente los orientados a campos

Audiovisuales.

Fuente: Información obtenida de la investigación.

El proyecto se ha realizado durante los meses de octubre y noviembre de 2017. En el aula, los alumnos han desarrollado las fases de búsqueda de información e ideas, de estructuración (historia y guion), y de montaje y edición de vídeo. En el aula, han sido creados pequeños platós de grabación, aunque la mayor parte de las grabaciones han tenido lugar en otros espacios fuera del aula, e incluso en entornos no universitarios, como entorno familiar (hogares), entorno urbano, entorno rural, dentro de vehículos, etc.

\subsection{Descripción del proyecto}

La metodología llevada a cabo en este proyecto pretende asumir los roles de la gran pantalla, creando grupos en el que cada componente tiene una labor, pero al mismo tiempo existen amplios espacios de trabajo en equipo para elaborar la idea, el proceso de grabación, y el proceso de montaje, existiendo otros muchos roles intermedios tales como el sonido, los efectos, el vestuario, el maquillaje, la búsqueda de ubicaciones, etc.

El tema seleccionado para todos los grupos fue «un viaje por la Bretańa», con la finalidad de que todos los grupos pudieran focalizar un tema de forma amplia y flexible, al mismo tiempo que pudieran relacionarlo con diversos contenidos curriculares de la asignatura de inglés del currículo español de Educación Primaria, abarcando simultáneamente aspectos como el folklore, los lugares, el arte, el paisaje, la moda, la música, la gastronomía, el deporte o la cultura en general.

La duración por cada cortometraje es entre 2 y 3 minutos, haciendo uso de cualquier técnica de grabación, sugiriendo las cercanas al campo de la animación. 
Figura 3. Esquema con los roles de los participantes del proyecto en cada uno de los grupos.

ROLES DE LOS PARTICIPANTES

(repartidos entre los participantes)

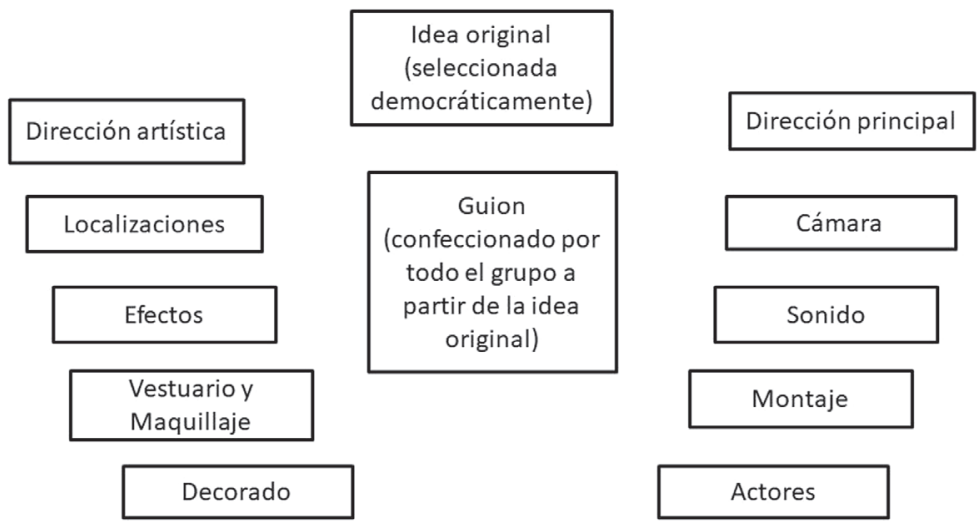

Además, se marcaron unas pautas, relacionadas con los contenidos teóricos de la asignatura, en la que se trataron aspectos relacionados con la percepción polisensorial, los Elementos del Lenguaje Visual y Plástico (ELVP) y sus relaciones de composición (Villafañe y Mínguez, 2002). Todo ello haciendo especial énfasis en los aspectos comunicativos de la imagen y su mensaje visual.

El proceso empleado en el proyecto tiene las siguientes fases:

1. Idea individual. Cada componente buscará la información necesaria para crear una idea, registrándola a través de bocetos, esquemas y un storyboard, sugiriendo personajes, materiales, ubicaciones, etc.

2. Todos los componentes del grupo (3), mostrarán sus ideas y seleccionarán una, modificándola de forma democrática, acorde a las opiniones del grupo completo, reformando el esquema inicial y el guion. Deben enumerar los materiales y ubicaciones, así como describir los ELPV trabajados y sus fines comunicativos.

3. Grabación: los componentes del grupo utilizarán todas las técnicas necesarias para grabar las imágenes (fotografía y video), cuidando especialmente los aspectos de composición fotográfica y cinematográfica.

4. Edición de video: los componentes del grupo utilizarán aquellos softwares de edición de video para montar los recursos visuales y sonoros (MovieMaker, Powerdirector, Pinnacle Studio, iMovie y Audacity). 
Figura 4. Captura de pantalla de «leer es viajar».

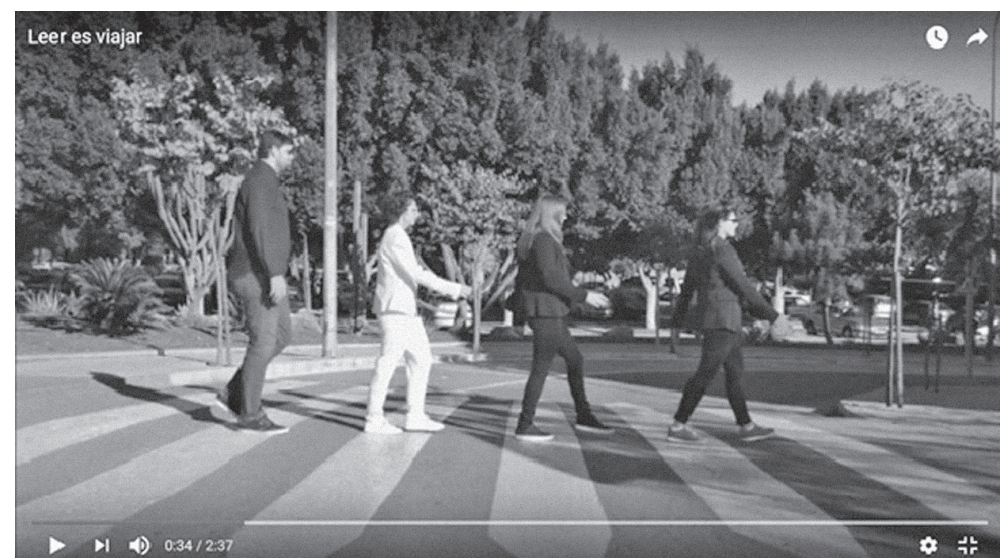

Fuente: Información obtenida de los informes escritos de Ángela Meseguer, María Navarro, Manuel Sánchez y Mari Cruz Villalba.

Figura 5. Captura de pantalla del montaje de «un viaje inesperado».

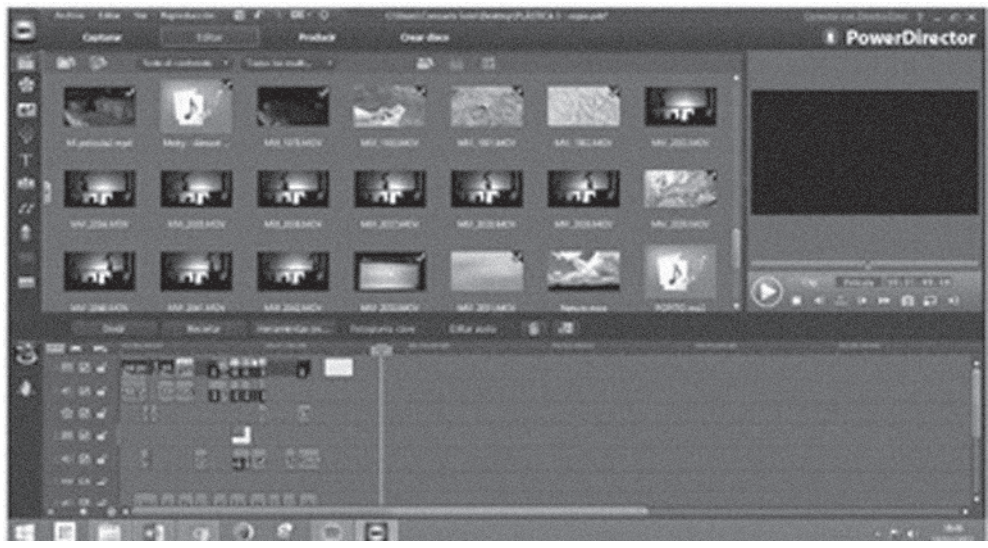

Fuente: Información obtenida de los informes escritos de Consuelo Soler, María José Peñalver y María del Carmen Molina.

Una vez finalizado, los alumnos utilizaron la plataforma de difusión de video YouTube, mediante la cual pudieron visualizarse un total de 16 trabajos, proyectándose en clase a modo de jornadas cinematográficas durante dos sesiones, y donde el alumnado pudo presentar y debatir cada cortometraje, creando momentos de discusión tras cada una de las visualizaciones. 
Tabla 2. Trabajos audiovisuales realizados por el alumnado

\begin{tabular}{ll}
\hline \multicolumn{1}{c}{ Título } & \multicolumn{1}{c}{ URL Youtube } \\
\hline Juan's Trip & https://www.youtube.com/watch?v=kJ7YdwG9WqI\&t=9s \\
Fashion trip & https://www.youtube.com/watch?v=X5a-tClQV8M \\
La mosca viajera & https://www.youtube.com/watch?v=ls2QikT1CKo \\
La cultura es aventura & https://youtu.be/tMRN07Y7Dlg \\
Una persona, varias culturas & https://www.youtube.com/watch?v=WzF7edXaQ-k\&t=2s \\
Vikings vs muslims: the battle & https://www.youtube.com/watch?v=pHdPS17LYxE \\
Hójase una vez & https://www.youtube.com/watch?v=0r4MwtuTIGM \\
Sin barreras & https://www.youtube.com/watch?v=H5R0BOdfcLU \\
Leer es viajar & https://www.youtube.com/watch?v=BqEtOF1SIWs \\
Un viaje inesperado & https://www.youtube.com/watch?v=o7zHbh6Fp6o \\
La mochila de tu vida & https://www.youtube.com/watch?v=MQtBH5-sIn8\&t=4s \\
Viajando a través de la música & https://youtu.be/dByAyQkPT7A \\
Viajando a través de la música & https://youtu.be/dByAyQkPT7A \\
Viaje descontaminante & https://youtu.be/jhEG6Qx1dII \\
El viaje de Ezequi & https://www.youtube.com/watch?v=n2vGsK_cKP8\&t=118s \\
Paisajes de cine & https://www.youtube.com/watch?v=UJ8hkVDHuoM \\
\hline
\end{tabular}

Fuente: Información obtenida de la investigación.

Sin embargo, en este trabajo no solo es interesante una metodología basada en proyectos y que los alumnos del Grado de Educación Primaria conocieran posibilidades didácticas para una futura praxis profesional como maestros, sino que analizamos las producciones realizadas y hacemos un testeo en varios bloques acerca de sus conocimientos y habilidades relacionadas con proyectos y recursos TIC en el aula, el uso de la imagen y otros aspectos relacionados, así como su opinión acerca de la factibilidad y versatilidad de este tipo de proyectos en el aula de Educación Primaria. Por tanto, una vez creadas y visualizadas las producciones audiovisuales, se procedió a la cumplimentación del test por parte del alumnado y a la valoración de cada uno de los trabajos.

\subsection{Valoración de la producción audiovisual}

La valoración del trabajo audiovisual se hace en función de la aplicación de los contenidos previos que se facilitaron al alumnado: relativas al proceso creativo, relativas a la variedad de elementos del lenguaje visual y plástico utilizados, relativas al carácter expresivo y comunicativo, relativas a la transversalidad y matices temáticos empleados, por último, relativas al proceso técnico audiovisual. A continuación, adjuntamos la parrilla con la que se evaluó la producción audiovisual. 
Tabla 3. Parrilla de valoración de los trabajos audiovisuales.

\begin{tabular}{|c|c|c|c|c|}
\hline & Nivel 0 & Nivel 1 & Nivel 2 & Nivel 3 \\
\hline $\begin{array}{l}\text { Proceso } \\
\text { creativo }\end{array}$ & $\begin{array}{l}\text { No trabaja } \\
\text { las fases } \\
\text { del proceso } \\
\text { creativo } \\
\text { salvo la de } \\
\text { elaboración. }\end{array}$ & $\begin{array}{l}\text { Trabaja } \\
\text { levemente } \\
\text { las fases } \\
\text { del proceso } \\
\text { creativo, e } \\
\text { incluso alguna } \\
\text { de ellas ni las } \\
\text { procesa. }\end{array}$ & $\begin{array}{l}\text { Trabaja todas } \\
\text { las fases } \\
\text { del proceso } \\
\text { creativo, } \\
\text { aunque puede } \\
\text { profundizar } \\
\text { más en alguna } \\
\text { de ellas. }\end{array}$ & $\begin{array}{l}\text { Trabaja todas } \\
\text { las fases } \\
\text { del proceso } \\
\text { creativo en } \\
\text { profundidad. }\end{array}$ \\
\hline $\begin{array}{l}\text { Variedad de } \\
\text { ELVP }\end{array}$ & $\begin{array}{l}\text { No incorpora } \\
\text { ELVP en su } \\
\text { producción. }\end{array}$ & $\begin{array}{l}\text { Incorpora } \\
\text { escasos y } \\
\text { poco variados } \\
\text { ELVP en su } \\
\text { producción. }\end{array}$ & $\begin{array}{l}\text { Incorpora } \\
\text { variados } \\
\text { ELVP en su } \\
\text { producción. }\end{array}$ & $\begin{array}{l}\text { Incorpora } \\
\text { y relaciona } \\
\text { abundantes } \\
\text { y variados } \\
\text { ELVP en su } \\
\text { producción. }\end{array}$ \\
\hline $\begin{array}{l}\text { Carácter } \\
\text { expresivo y } \\
\text { comunicativo }\end{array}$ & $\begin{array}{l}\text { No ofrece } \\
\text { un carácter } \\
\text { expresivo y } \\
\text { comunicativo } \\
\text { debido a la } \\
\text { nula utilización } \\
\text { de recursos } \\
\text { y elementos } \\
\text { visuales y } \\
\text { plásticos. }\end{array}$ & $\begin{array}{l}\text { Ofrece un } \\
\text { ligero carácter } \\
\text { expresivo y } \\
\text { comunicativo } \\
\text { debido a la } \\
\text { escasez o } \\
\text { extremada } \\
\text { sencillez de } \\
\text { los elementos } \\
\text { utilizados. }\end{array}$ & $\begin{array}{l}\text { Ofrece un } \\
\text { carácter } \\
\text { expresivo y } \\
\text { comunicativo } \\
\text { debido a la } \\
\text { utilización } \\
\text { de recursos } \\
\text { y elementos } \\
\text { visuales y } \\
\text { plásticos. }\end{array}$ & $\begin{array}{l}\text { Ofrece un } \\
\text { carácter } \\
\text { expresivo y } \\
\text { comunicativo } \\
\text { debido la } \\
\text { abundante } \\
\text { utilización y } \\
\text { combinación } \\
\text { de recursos } \\
\text { y elementos } \\
\text { visuales y } \\
\text { plásticos. }\end{array}$ \\
\hline $\begin{array}{l}\text { Transversalidad } \\
\text { temática }\end{array}$ & $\begin{array}{l}\text { Trabaja una } \\
\text { temática } \\
\text { haciendo un } \\
\text { constante uso } \\
\text { de tópicos y } \\
\text { sin profundizar } \\
\text { en aspectos } \\
\text { de la cultura } \\
\text { británica. }\end{array}$ & $\begin{array}{l}\text { Trabaja una } \\
\text { temática } \\
\text { haciendo uso } \\
\text { de tópicos y } \\
\text { profundizando } \\
\text { levemente } \\
\text { en aspectos } \\
\text { de la cultura } \\
\text { británica. }\end{array}$ & $\begin{array}{l}\text { Trabaja una } \\
\text { temática sin } \\
\text { hacer uso } \\
\text { de tópicos y } \\
\text { profundizando } \\
\text { en aspectos } \\
\text { de la cultura } \\
\text { británica. }\end{array}$ & $\begin{array}{l}\text { Trabaja una } \\
\text { temática sin } \\
\text { hacer uso } \\
\text { de tópicos y } \\
\text { profundizando } \\
\text { en aspectos } \\
\text { de la cultura } \\
\text { británica, } \\
\text { adaptándolos } \\
\text { al estilo del } \\
\text { grupo. }\end{array}$ \\
\hline
\end{tabular}




\begin{tabular}{|c|c|c|c|c|}
\hline & Nivel 0 & Nivel 1 & Nivel 2 & Nivel 3 \\
\hline $\begin{array}{l}\text { Proceso técnico } \\
\text { y ejecución }\end{array}$ & $\begin{array}{l}\text { Utiliza y } \\
\text { ejecuta } \\
\text { insuficientes } \\
\text { herramientas } \\
\text { y técnicas de } \\
\text { elaboración } \\
\text { plástica y } \\
\text { audiovisual. } \\
\text { Además no } \\
\text { las utiliza } \\
\text { correctamente. }\end{array}$ & $\begin{array}{l}\text { Utiliza y } \\
\text { ejecuta } \\
\text { herramientas } \\
\text { y técnicas de } \\
\text { elaboración } \\
\text { plástica y } \\
\text { audiovisual, } \\
\text { pero puede } \\
\text { hacer mejor } \\
\text { uso de ellas. }\end{array}$ & $\begin{array}{l}\text { Utiliza y } \\
\text { ejecuta } \\
\text { adecuadamente } \\
\text { herramientas } \\
\text { y técnicas de } \\
\text { elaboración } \\
\text { plástica y } \\
\text { audiovisual. }\end{array}$ & $\begin{array}{l}\text { Utiliza y } \\
\text { ejecuta } \\
\text { adecuadamente } \\
\text { herramientas } \\
\text { y técnicas de } \\
\text { elaboración } \\
\text { plástica y } \\
\text { audiovisual. } \\
\text { Además no se } \\
\text { conforma sino } \\
\text { que contrasta } \\
\text { recursos } \\
\text { técnicos para } \\
\text { optimizar su } \\
\text { trabajo. }\end{array}$ \\
\hline
\end{tabular}

Fuente: Información obtenida de la investigación.

\subsubsection{Valoración relativa al proceso creativo (búsqueda de información e ideas)}

Este aspecto se realiza en función de todo el proceso de trabajo, es decir, no solo de la elaboración y resultado del producto final, ya que este último puede o no responder a un proceso regular de búsqueda de información, búsqueda y concreción de ideas. Mediante la observación del trabajo diario de cada grupo, se ha valorado la búsqueda y procesado información referente a temáticas, posibles técnicas de animación, posibles estilos y al estudio de posibles elementos visuales que pueden repercutir en el carácter expresivo y conceptual. Para esta fase, resulta imprescindible la visualización de otros videos, lecturas concernientes a diversas temáticas, así como realizar lecturas previas acerca del lenguaje visual, realizar un listado con las primeras ideas, posibles materiales y el tipo de lenguaje acorde a los destinatarios. Para realizar una animación, sería el momento de pensar en personajes, posibles guiones, escenarios, etc.

En este sentido, se dedicaron varias sesiones a configurar la base de cada propuesta y como se puede comprobar, a continuación, la valoración positiva que contemplamos en este apartado se ve reflejada en los sucesivos. 


\subsubsection{Valoración relativa a la variedad de elementos del lenguaje visual $y$ plástico}

En la mayoría de los trabajos, prevalece un amplio surtido de elementos del lenguaje visual y plástico. En un tercio de los trabajos, existe un claro predominio de elementos superficiales y planos, como la línea y el plano, frente a la escasez de elementos de volumen y texturas. El elemento predominante en todos los trabajos es el color, buscado en diversos materiales, aunque también aplicándolo a modo pictórico en algunas ocasiones. Salvo ese tercio de trabajos que comentamos anteriormente, elementos también predominantes son la textura y el volumen, ya que integran recursos y materiales procedentes de la vida cotidiana.

Figura 6. Captura de pantalla «sin barreras».

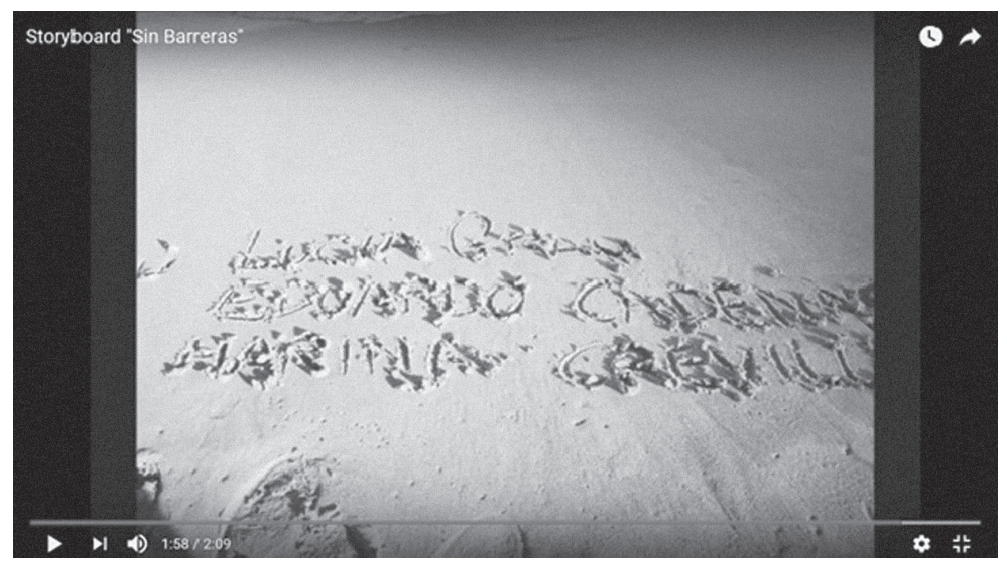

Fuente: Información obtenida de los informes escritos de Eduardo Cadenas, María Crevillen y Lucia Grau.

\subsubsection{Valoración relativa al carácter expresivo y comunicativo}

Es importante distinguir entre el valor expresivo de los elementos (que pretende expresar algo) y el valor puramente decorativo. Omitir toda aquella información visual que sea meramente decorativa o nada expresiva.

Para enfatizar en el valor comunicativo y expresivo, resulta transcendente observar el material u objetos que nos rodean: sus puntos, líneas, planos, formas, volumen texturas o color; ya que podrían ser utilizados o reutilizados como material expresivo, que, descontextualizados e integrados en el trabajo, ofrecen una alta carga simbólica y expresiva. 
En términos globales, en los trabajos realizados, los elementos visuales y plásticos seleccionados ofrecen una alta carga expresiva. El contraste entre elementos planos y elementos volumétricos ofrece mayor impacto visual, frentes aquellos que se limitan a utilizar elementos planos.

A nivel compositivo, la relación entre elementos es bastante variada. Los trabajos hacen uso de relaciones espacio-temporales (tamaño, escala, proporción y formato), relaciones de temporalidad (tensión y ritmo) y relaciones de composición (peso visual, direcciones visuales, simetría y movimiento). Todo ello incrementa el nivel comunicativo y expresivo de las imágenes, favoreciendo en dinamismo y la recepción del mensaje visual.

Figura 7. Captura de pantalla de «Un viaje inesperado».

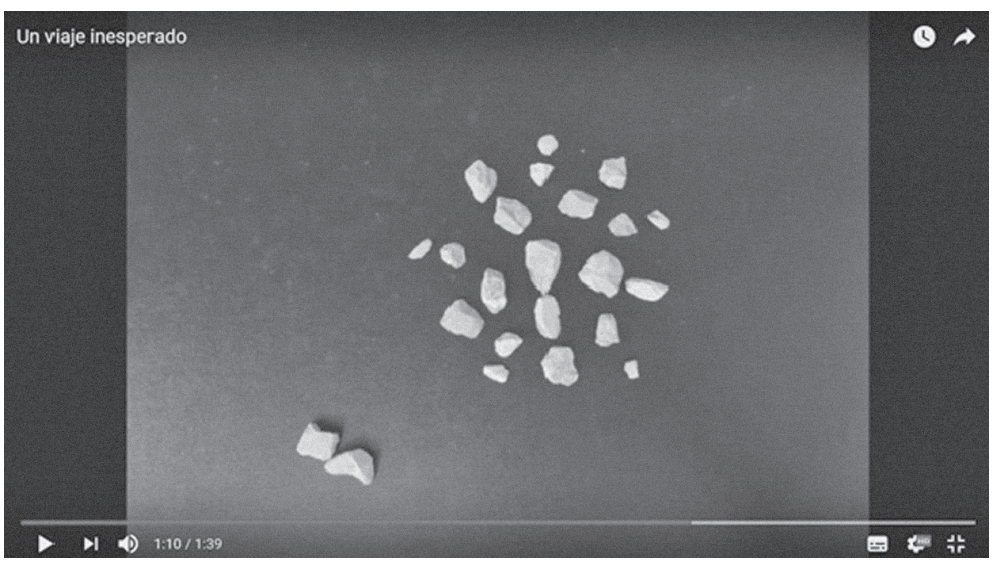

Fuente: Información obtenida de los informes escritos de Consuelo Soler, María José Peñalver y María del Carmen Molina.

\subsubsection{Valoración relativa a la transversalidad y matices temáticos empleados}

En esta línea que tanto insistimos en el aula, la valoración resulta muy positiva en la elaboración de todos los trabajos. De forma general en el grupo, resulta muy interesante la transversalidad de los temas tratados, no repetidos en ninguno de los grupos de trabajo, destacando aspectos como la música, la literatura, la moda, la gastronomía, el paisaje, el deporte y otras temáticas más personales. También resaltan lenguajes empleados, la mayoría con un cierto carácter lúdico, otros con un carácter más romántico, íntimo, lírico y metafórico. 
Figura 8. Captura de pantalla de «un viaje inesperado».

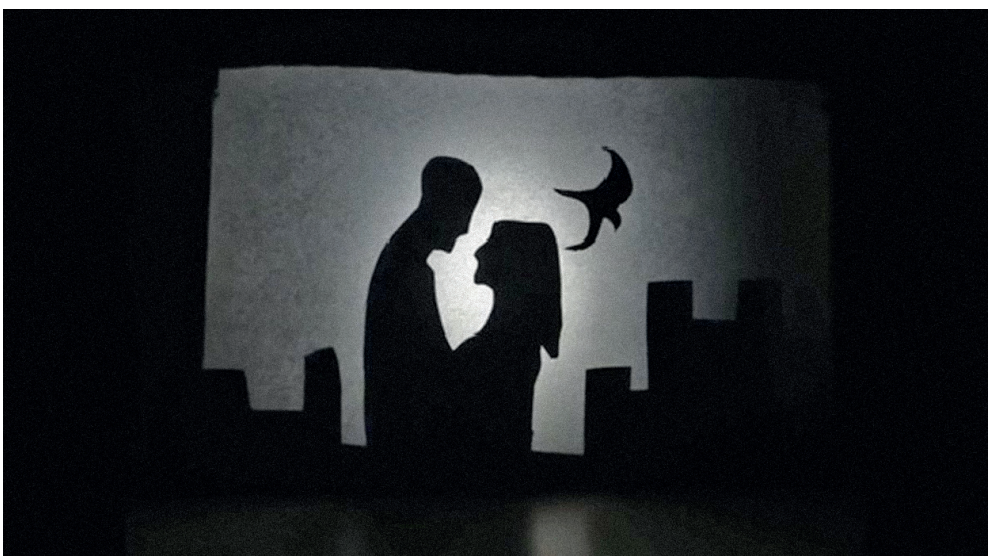

Fuente: Información obtenida de los informes escritos de Consuelo Soler, María José Peńalver y María del Carmen Molina.

Tanto a nivel sonoro o de imagen, en la totalidad de los trabajos, se han utilizado recursos vinculados con el concepto de viaje: vía de tren, automóvil, bicicleta, avión, estaciones o aeropuertos, maletas, etc. En algunos de los trabajos, se producen saltos temporales que narran la cultura y tradición de zonas británicas en diferentes momentos. Algunos de los trabajos contrastan la cultura británica con la espańola, utilizando el concepto de trayecto como hilo conductor temático.

\subsubsection{Valoración relativa al proceso técnico audiovisual (grabación y edición de video)}

Dar forma a la idea, a través de la técnica, no siempre es una tarea fácil. Para ello, es importante haber trabajado las fases preparatorias a la elaboración, y tener los conceptos y objetivos bien claros, de ello depende el nivel conceptual y expresivo alcanzado en el producto final.

En la mayoría de las producciones creadas, los alumnos han hecho buen uso de su capacidad de síntesis y han descartado aquellos recursos que puedan parecer excesivos, aquellos que nos desvían del mensaje y objetivo principal. Una frase que hemos recordado durante todo el proceso es «menos es más». Esta frase ha sido utilizada especialmente en las fases de grabación y edición de video. Para ello, nuestros alumnos han sabido simplificar los recursos al máximo, seleccionando los recursos expresivos mínimos para cada momento, 
y eligiendo los planos más dinámicos y sencillos que resumen a la mínima expresión los conceptos que han querido transmitir. Tanto en el momento de grabación como en el de montaje audiovisual, han aparecido matices nuevos con respecto a las ideas originales, circunstancia promovida por la actitud abierta del alumnado que ha sabido conllevar para añadir y reformular cada propuesta.

\subsection{Pretest}

Con la finalidad de conocer la evolución del alumnado tras este proyecto, se ha realizado un pretest que contextualice el nivel y situación previa. Para ello, los alumnos cumplimentaron un cuestionario con la finalidad de conocer sus conocimientos y experiencia en ABP, especialmente relacionados con disciplinas TIC y audiovisuales, conocimiento y experiencia en la utilización de TIC, así como su conocimiento y experiencia con materiales, elementos y relaciones del lenguaje visual y plástico.

\section{Resultados}

A modo de contextualización, el proyecto se ha llevado a cabo en un grupo 44 alumnos, 36 son mujeres y 8 hombres, todos los estudiantes pertenecientes a la Mención de Lengua Extranjera Inglés (cuarto curso), en la asignatura Desarrollo del Lenguaje Visual y Plástico (cuarto curso) del Grado de Educación Primaria. Este curso de la titulación implica que los alumnos han estado realizando las Prácticas Externas I (segundo curso) y II (tercer curso) en distintos centros de Educación Primaria, donde han tenido que diseñar y llevar a la práctica actividades formativas para niños, teniendo la oportunidad de llevar a la práctica herramientas TIC. La edad de los alumnos está comprendida entre los 21 y 23 años. A continuación, exponemos algunas de las cuestiones que se plantearon al alumnado, así como sus respuestas:

Tabla 4. Cuestiones más relevantes del pretest.

\begin{tabular}{ll}
\hline \multicolumn{1}{c}{ Enunciados } & \multicolumn{1}{c}{ Respuestas } \\
\hline $\begin{array}{l}\text { P.1. Antes de cursar la asignatura «Desarrollo del } \\
\text { Lenguaje Visual y Plástico», ¿́sabías lo que es un } \\
\text { proyecto didáctico audiovisual? }\end{array}$ & $\begin{array}{l}\text { R. 30 alumnos responden que si, } \\
14 \text { que no. }\end{array}$ \\
\hline $\begin{array}{l}\text { P.4.* Recursos sonoros (por ejemplo, música, } \\
\text { grabaciones, etc.). }\end{array}$ & $\begin{array}{l}\text { R. 4 alumnos indican nunca, 12 } \\
\text { rara vez, 10 alguna vez, 16 muchas } \\
\text { veces, 2 siempre. }\end{array}$ \\
\hline
\end{tabular}




\begin{tabular}{ll}
\hline \multicolumn{1}{c}{ Enunciados } & \multicolumn{1}{c}{ Respuestas } \\
\hline $\begin{array}{l}\text { P.5* Recursos audiovisuales (por ejemplo videos, } \\
\text { películas, etc.). }\end{array}$ & $\begin{array}{l}\text { R. 2 alumnos indican nunca, 12 } \\
\text { rara vez, 12 alguna vez, 16 muchas } \\
\text { veces, 2 siempre. }\end{array}$ \\
\hline $\begin{array}{ll}\text { P.6* Programas de edición audiovisual (fotografía } \\
\text { y video). }\end{array}$ & $\begin{array}{l}\text { R. 8 alumnos indican rara vez, 19 } \\
\text { alguna vez, 15 muchas veces, 2 } \\
\text { siempre. }\end{array}$ \\
\hline
\end{tabular}

P.7* Recursos procedentes de Internet (por ejemplo, blog de aula, web quest, etc.).
R. 7 alumnos indican nunca, 14 rara vez, 10 alguna vez, 10 muchas veces, 3 siempre.
P.11* Cuenta en youtube u otra plataforma en red.
R. 1 alumnos indican nunca, 2 rara vez, 3 alguna vez, 5 muchas veces, 32 siempre.
P.12 Conozco las fases del proceso creativo y las utilizo para buscar ideas y crear recursos educativos, en este caso recursos visuales y audiovisuales.
R. 16 alumnos manifiesta no o tener dudas al respecto, 24 manifiestan que sí.
P.14 Cuando utilizo o creo recursos visuales y audiovisuales tengo en cuenta las posibilidades expresivas que pueden ofrecer cada uno de los ELVP (el punto, la línea, el plano, las formas, las texturas, el volumen y el color).
R.17 alumnos manifiesta no o tener dudas al respecto, 27 manifiestan que sí.

Fuente: Información obtenida de la investigación.

* Respecto a la frecuencia o el grado de conocimiento con la que el alumnado ha utilizado un recurso en su experiencia docente en Educación Primaria (Prácticas Externas I y II).

\subsection{Test}

Tras la cumplimentación del pre-test y la elaboración del proyecto audiovisual, se realiza un test final con el propósito de adquirir información acerca de la evolución del alumnado respecto a sus conocimientos y habilidades adquiridas, y su opinión concerniente al proyecto didáctico audiovisual realizado. Todo ello respecto a la utilización de recursos TIC y audiovisuales, y herramientas didácticas, visuales y plásticas. A continuación, exponemos algunas de las cuestiones que se plantearon al alumnado, así como sus respuestas. 
Tabla 5. Cuestiones más relevantes del postest.

\begin{tabular}{ll}
\hline \multicolumn{1}{c}{ Enunciados } & \multicolumn{1}{c}{ Respuestas } \\
\hline $\begin{array}{l}\text { P.15: Tengo formación suficiente para usar } \\
\text { medios audiovisuales como recurso educativo } \\
\text { en Educación Primaria. }\end{array}$ & $\begin{array}{l}\text { R.17 alumnos manifiestan no o tener } \\
\text { dudas al respecto, 27 manifiestan que sí. }\end{array}$ \\
\hline $\begin{array}{l}\text { P.16 Conozco los aspectos básicos del } \\
\text { lenguaje audiovisual. }\end{array}$ & $\begin{array}{l}\text { R.17 alumnos manifiestan no o tener } \\
\text { dudas al respecto, 27 manifiestan que sí. }\end{array}$ \\
$\begin{array}{l}\text { P.19: Sé editar imágenes con programas } \\
\text { informáticos (Por ejemplo: Photoshop, }\end{array}$ & $\begin{array}{l}\text { R.13 alumnos manifiestan no o tener } \\
\text { dudas al respecto, 29 manifiestan que sí. }\end{array}$ \\
$\begin{array}{l}\text { Gimp, Photoscape...). } \\
\begin{array}{l}\text { P.20 Sé editar vídeo y sonido con programas } \\
\text { informáticos (por ejemplo, MovieMaker, }\end{array}\end{array}$ & $\begin{array}{l}\text { R.6 alumnos manifiestan no o tener } \\
\text { dudas al respecto, 38 manifiestan que sí. }\end{array}$ \\
\hline $\begin{array}{l}\text { Audacity, Powerdirector, iMovie...). } \\
\text { P.1 Cow }\end{array}$ &
\end{tabular}

P.21 Conozco técnicas de animación para la

R.20 alumnos manifiestan no o tener grabación de vídeos (StopMotion, animación dudas al respecto, 24 manifiestan que sí. digital, animación digital 3D).

P.23 Sé cómo se planifica y guioniza un vídeo y lo he llevado a la práctica realizando storyboard.
R.3 alumnos manifiestan no o tener dudas al respecto, 41 manifiestan que sí.

P.24 Considero que el vídeo es un recurso $\quad$ R. Todos los manifiestan que sí. útil para promover aprendizajes en el alumnado de Educación Primaria como parte de una metodología basada en proyectos.

P.26 Me ha resultado difícil trabajar en grupo un proyecto audiovisual.

R.42 alumnos manifiestan no o tener dudas al respecto, 2 manifiestan que sí.

P.29 Considero que es fundamental que el maestro de Educación Primaria sepa diseñar vídeos y crear animaciones.

R.15 alumnos manifiestan no o tener dudas al respecto, 29 manifiestan que sí.

P.30 Considero que el video y la creación de animaciones es un recurso divertido y motivador para Educación Primaria.

P.33 Considero que la metodología basada en proyectos audiovisuales de animación es muy factible para investigar aspectos profundos de la cultura del Reino unido (moda, música, gastronomía, entorno, forma de vida...), ayudando a que la interpretación del currículum sea lo más cercana posible a la realidad.
R.1 alumnos manifiestan no o tener dudas al respecto, 43 manifiestan que sí.

R.4 alumnos manifiestan no o tener dudas al respecto, 40 manifiestan que sí. 


\begin{tabular}{ll}
\hline \multicolumn{1}{c}{ Enunciados } & \multicolumn{1}{c}{ Respuestas } \\
\hline $\begin{array}{l}\text { P.34 Considero que en la creación de } \\
\text { recursos visuales y audiovisuales, para buscar } \\
\text { una mayor carga sensorial es importante } \\
\text { potenciar el Lenguaje Visual y Plástico. }\end{array}$ & $\begin{array}{l}\text { R.11 alumnos manifiestan no o tener } \\
\text { dudas al respecto, 33 manifiestan que sí. }\end{array}$ \\
\hline $\begin{array}{l}\text { P.35 Considero que cuando creo recursos } \\
\text { visuales y audiovisuales tengo en cuenta }\end{array}$ & $\begin{array}{l}\text { R.18 alumnos manifiestan no o tener } \\
\text { dudas al respecto, 26 manifiestan que sí. }\end{array}$ \\
$\begin{array}{l}\text { las relaciones visuales y plásticas y de } \\
\text { composición (tamańo, contraste, equilibrio, } \\
\text { simetría, peso, dirección, movimiento) entre } \\
\text { los diferentes ELVP. }\end{array}$ \\
$\begin{array}{l}\text { P.36 Considero que es necesario el uso de } \\
\text { materiales cotidianos como fuente material } \\
\text { y expresiva en la creación de recursos } \\
\text { didácticos visuales y audiovisuales, ya que } \\
\begin{array}{l}\text { ofrecen posibilidades interactivas y aportan } \\
\text { riqueza sensorial. }\end{array}\end{array}$ \\
\hline
\end{tabular}

P.38 Considero que sé utilizar la fotografía y programas de edición para captar y hacer R.11 alumnos manifiestan no o tener dudas al respecto, 33 manifiestan que sí. de uso propio materiales que pueden ser de interés en la creación de recursos visuales y audiovisuales.

Fuente: Información obtenida de la investigación.

\section{DisCUSIÓN Y CONCLUSIONES}

Como se ha podido comprobar en la introducción y en el estado de la cuestión, hay constancia de que, durante décadas, se han realizado gran cantidad de proyectos educativos cinematográficos. Lo relevante está precisamente en la continuidad de aquellas metodologías activas, basadas en hacer cine, en las que confiaron y amaron docentes, como Don Pascual Vázquez, y que se han dilatado hasta la actualidad con sus debidas adaptaciones tecnológicas, económicas y sociales.

Tras la valoración de las producciones audiovisuales y de los resultados del pretest y postest realizados por el alumnado, podemos llegar a las siguientes conclusiones:

Antes de llevar a cabo esta propuesta, la mayoría de los alumnos sabían lo que era un proyecto didáctico audiovisual (P.1). Con respecto a la experiencia del alumnado en las Prácticas Externas cursadas (antes del cuarto curso), algo 
menos de la mitad del alumnado ha utilizado recursos audiovisuales, lo que respalda la importancia de este trabajo, ya que ha permitido que todos los alumnos trabajen las TIC con un enfoque pedagógico para su futura labor docente, además de afianzar su formación para aquellos que ya tenían conocimientos previos. Por otra parte, la mitad del alumnado ha utilizado recursos sonoros, recursos procedentes de internet (web quest, blog de aula, etc.). Un dato muy relevante es que casi todo el alumnado tiene cuenta y utiliza con mucha frecuencia plataformas de difusión de video como YouTube, además, algunos de ellos las han llegado a utilizar en el diseño y aplicación de actividades para niños en las prácticas escolares. Sin embargo, solo un tercio del alumnado ha utilizado programas de edición de video (P.4 a P.11). Con respecto al uso de las fases del proceso creativo para llevar a cabo recursos visuales y audiovisuales, un dato esperanzador es que al menos la mitad del alumnado lo efectúa; es decir, que el alumno procede a buscar, contrastar y seleccionar información para posteriormente elaborar ideas y emprender la fase de elaboración. En referencia al uso de los ELVP, la mayoría del alumnado tiene en consideración sus posibilidades expresivas cuando crea recursos visuales y audiovisuales (P.12 a P.14).

Una vez materializada la propuesta, el alumnado manifiesta tener formación suficiente para usar medios audiovisuales como recurso educativo en Educación Primaria, así como conocer los aspectos básicos del lenguaje audiovisual y usarlos para planificar y diseñar recursos educativos (P.15 a P.23). La mayoría del alumnado considera que los recursos audiovisuales son útiles para trabajar contenidos en la etapa de Educación Primaria (P.24), además, consideran que saben utilizar programas básicos de edición de imagen y video. También hemos podido contrastar que nuestros alumnos han terminado el proyecto conociendo algunas técnicas de animación y utilizando la técnica del storyboard para estructurar y secuenciar sus trabajos audiovisuales, así como para enseñar a su futuro alumnado. Además, el alumnado opina que le parece fácil y divertido trabajar en grupo un proyecto audiovisual (P.30). La mayoría de los alumnos ven factible que los alumnos de la etapa de Educación Primaria diseñen vídeos como parte de una metodología basada en proyectos, además, y en este caso, la consideran realizable para investigar aspectos profundos de la cultura del Reino unido (moda, música, gastronomía, entorno, forma de vida...), ayudando a que la interpretación del currículum sea lo más cercana posible a la realidad. Al respecto, nuestro alumnado no ha tenido dificultades para adaptar su proyecto audiovisual a los contenidos y estándares de aprendizaje del currículum de Educación Primaria, e incluso, han sido capaces de contemplar otros aspectos que no aparecen en el currículum, acercándose 
más a la cultura real del Reino Unido (P.29 y P.33). En este sentido, nuestro alumnado contempla múltiples posibilidades para que sus futuros alumnos aprendan aplicando todas las fases del proceso creativo, emprendiendo tareas tanto de forma autónoma como de forma grupal (P.26), fundamentalmente en las fases de búsqueda y contraste de información como en aquellas que se basan en la creación de ideas y elaboración de producción final (cortometrajes).

Concerniente a los aspectos visuales, la mayor parte de los discentes opina que para buscar una mayor carga sensorial es importante potenciar el Lenguaje Visual y Plástico, que cuando crean recursos visuales y audiovisuales tienen en consideración las relaciones visuales y plásticas, y de composición entre los diferentes ELVP, así como la necesidad del uso de materiales cotidianos e imágenes procedentes de internet como fuente material y expresiva, ya que ofrecen posibilidades interactivas y aportan riqueza sensorial. El uso de materiales, durante el proceso, genera una serie de experiencias que enriquecen el aprendizaje y permite estudiar una temática más en profundidad (P.34 a P.36).

Como puede apreciarse en los resultados, el uso de metodologías activas ABPA, como la utilizada en proyectos como el que aquí se presenta, ofrece posibilidades y recursos que pueden llegar a ser atractivos para el alumnado (P.30). Además, aparece la posibilidad de reconvertir dispositivos digitales y software (móviles, cámaras, redes de difusión, programas de retoque audiovisual) muy frecuentes como recursos lúdicos a recursos didácticos. En este sentido, se puede destacar que la totalidad del alumnado considera que el vídeo es un recurso útil para promover aprendizajes en el alumnado de Educación Primaria como parte de una metodología basada en proyectos, utilizando herramientas que utilizan diariamente y que son muy familiares en la mayoría de los entornos familiares, fundamentalmente si son utilizadas de forma grupal en los procesos de grabación, edición y difusión.

Los proyectos creativos y audiovisuales, como el que aquí se presentan, podrían utilizarse no solo como método con el que desarrollar contenidos curriculares, sino como medio y recurso transformador, potenciando así mismo la cooperación social, el compromiso, y aprendizaje cívico y democrático a través de distintos ejes temáticos. Por tanto, consideramos esencial la divulgación de propuestas como la que hoy presentamos, ya que su repercusión puede resultar transcendental para que el futuro docente conozca y adquiera este tipo de líneas metodológicas, acordes a nuestra realidad social, económica y tecnológica. 


\section{REFERENCIAS BIBLIOGRÁFICAS}

Acaso, M. (2009). La educación artística no son manualidades. Nuevas prácticas en la enseñanza de las artes y la cultura visual. Madrid: Catarata.

Arenas, A. (1995). La televisión como herramienta didáctica. Comunicar, 4. Recuperado de https://www.revistacomunicar.com/index.php?contenido= detalles\&numero $=4 \&$ articulo $=04-1995-10$

Bellido, A. (1998). El aprendizaje del cine. Comunicar, 11(6). Recuperado de https://www.revistacomunicar.com/index.php?contenido=detalles\&nume ro $=11$ \&articulo $=11-1998-03$

Calzadilla, M. (2002). Aprendizaje colaborativo y tecnologías. Revista Iberoamericana de Educación, 59(4). https://doi.org/10.35362/rie2912868

Clarembeaux, M. (2010). Educación en cine: memoria y patrimonio. Comunicar, 35(18). https://doi.org/10.3916/C35-2010-02-02

Fandos, M. (1994). El vídeo y su papel didáctico en Educación Primaria. Comunicar, 2. Recuperado de https://www.revistacomunicar.com/index. php? contenido $=$ detalles $\&$ numero $=2 \&$ articulo $=02-1994-13$

Ferro, C., Martínez, A. y Otero, M.C. (2009). Ventajas de uso de las TIC en el proceso de enseñanza-aprendizaje desde la óptica de los docentes universitarios españoles. Revista electrónica de Tecnología Educativa, 29. Recuperado de http://biblioteca.universia.net/html_bura/ficha/params/title/ventajasuso-tics-proceso-enseñanza-aprendizaje-optica-docentes-universitariosespañoles/id/47702358.html

García-Valcárcel, A., Hernández, A. y Recamán, A. (2012). La metodología del aprendizaje colaborativo a través de las TIC: una aproximación a la opinión de profesores y alumnos. Revista Complutense de Educación, 23(1), 161-188. https://doi.org/10.5209/rev_RCED.2012.v23.n1.39108

García-Valcárcel, A., Basilotta, V. y López, C. (2014). Las TIC en el aprendizaje colaborativo en el aula de Primaria y Secundaria. Comunicar, 42, 65-74.

Hernández, A. y Martín, J. (2017). Concepciones de los docentes no universitarios sobre el aprendizaje colaborativo con tic. Educación XX1, 11(1). https://doi.org/10.5944/educxx1.17508

Hervás, D. (2015). ABPA, Aprendizaje Basado en Proyectos Artísticos. Aula de Secundaria. Barcelona: Graó.

Marín-Viadel, R. (2003). Didáctica de la educación artística. Madrid: Pearson Educación.

Marzábal, I. y Arocena, C. (2016). Películas para la educación. Aprender viendo cine, aprender a ver cine. Madrid: Cátedra. 
Miravalles, L. (1998). Como disfrutar del cine en el aula. Comunicar, 11(6). https://doi.org/10.3916/C11-1998-10

Morilla, M. (1994). Televisión escolar «Las Montańas». Comunicar, 3. Recuperado de https://www.revistacomunicar.com/index.php?contenido=detalles\&nu mero $=3$ \&articulo $=03-1994-06$

Mudet, A., Beltran, A. y Moreno, A. (2015). Arte como herramienta social y educativa. Revista Complutense de Educación, 26(2), 315-329. https://doi. org/10.5209/rev_RCED.2015.v26.n2.43060

Piscitelli, A. (2009). Nativos digitales. Dieta cognitiva, inteligencia colectiva y arquitecturas de la participación. Buenos Aires: Santillana.

Pérez, M. y Aguaded, I. (1994). Lenguaje y nuevos lenguajes. Comunicar, 2. Recuperado de https://www.revistacomunicar.com/index.php?contenido= detalles\&numero $=2 \&$ articulo $=02-1994-05$

Prendes, M., Castañeda, L. y Gutierrez, I. (2010). Competencias para el uso de TIC de los futuros maestros. Comunicar, 35(18). https://doi.org/10.3916/ c35-2010-03-11

Roldán, J. y Marín-Viadel, R. (2014). Metodologias artísticas de investigación en educación. Málaga: Aljibe.

Ruiz, F. (1994). Cine y enseñanza. Comunicar, 3. Recuperado de https://www. revistacomunicar.com/index.php?contenido $=$ detalles $\&$ numero $=3 \&$ ar ticulo $=03-1994-10$

Valencia Extra (2016). Educación y el Institut Valencià de Cultura organizan conjuntamente la jornada Edusiona't amb les arts. Recuperado de http://valenciaextra.com/es/educacio-linstitut-valencia-de-cultura-organitzen-conjuntament-la-jornada-edusionat-amb-les-arts/

Villafañe, J. y Mínguez, N. (2002). Principios de teoría general de la imagen. Madrid: Piramide. 